\title{
Phytosanitary products use method in cowpea production in the commune of adjohoun, Benin
}

\author{
M. Marlène P. MICHOZOUNNOU ${ }^{1 *}$, Flavien DOVONOU ${ }^{2}$, B. Mathieu HOUNSOU ${ }^{1}$ and \\ K. Euloge AGBOSSOU ${ }^{1}$ \\ ${ }^{1}$ Laboratory for Hydraulics and Water Control, University of Abomey-Calavi, Benin. \\ ${ }^{2}$ Laboratory for Applied Hydrology of Abomey-Calavi University (LHA / FAST / UAC) 01 BP 4521 Cotonou, \\ Benin. Tel: (00229)21150567. \\ *Corresponding author; E-mail: michomarlene@yahoo.fr; Tel: 00 (229) $95714264197317954 / 97317954$
}

\begin{abstract}
This study aimed at identifying the chemical pesticides used in cowpea production and their different ways of use in the Adjohoun commune, in the South East of Benin. Thus, 323 farmers have been surveyed and the observations of their agronomic practices have allowed us to collect information on water contamination due to the use of pesticides. The chemical control has been identified as the main method to control the pests. Nevertheless, farmers recognize the effects of the synthetic pesticides use and are informed about the use of essences to control pests. However, few of them use botanical pesticides against pests. But, they are ready to use botanical pesticides if they are available, accessible, effective and cheap, to overcome the effects of chemical pesticides on health and environment. This study showed that various types of chemical pesticides such as COTALM P 218 EC, CYPERCAL 50 EC, Phostoxin etc...were used. The sources of the environmental risks are the parallel pesticides supply channels, the cleansing of the spreading equipment in water sources (about $85 \%$ of the farmers do that) and the non-compliance with the technical guidelines of the pesticides use. The risk assessment allowed us to highlight the health-related risks, surface water pollution risks and soils contamination risks. So, best agronomic practices are essential for a sustainable exploitation of the natural resources in this commune.
\end{abstract}

(C) 2018 International Formulae Group. All rights reserved.

Keywords: Cowpea, chemical pesticides, risk.

\section{INTRODUCTION}

Population growth, the reduction of agricultural land per capita and the uncontrolled exploitation of natural resources in Benin have led to food production with the use of chemical inputs. The Adjohoun commune has a high population density (243 inhabitants $/ \mathrm{km}^{2}$ ) according to the last RGPH (General Population and Housing Census) compared whith the national density (87 inhabitants / $\mathrm{km}^{2}$ ) (INSAE, 2014). As agriculture is the activity involving more than $80 \%$ (INSAE, 2004) of the active population in the Commune, it results in the overexploitation of land and a reduction or nearly an insistence of fallow periods. Low yields due to pest attack lead farmers to use agricultural inputs. Thus in the cowpea production, to fight against harmful insects, chemical products such as COTALM P 218 EC, CYPERCAL 50 EC, Phostoxin etc. are used as chemical insecticides to increase yield. However, the use and handling of these insecticides must comply with safety rules. The right choice of insecticides and their proper use are very important factors to 
consider. The excessive use of insecticides in the conservation of food against pests has serious consequences for the health of users, consumers and the environment and often leads to the elimination of insects with ecological benefits and develops resistance in some insect pests (Sanborn et al., 2004; Pazou et al., 2006a; Pazou et al., 2006b). Sometimes more serious consequences such as infertility or cancers, immune deficiencies, neurodevelopmental and behavioural disorders, metabolic disorders and diabetes are observed (Idrissi et al., 2010). The low level of education of producers and traders entails that they are unaware of how insecticides are used, which increases the risk of poisoning. In addition, they do not have the information to make the connection between the pest, its damage, the product to be used, its dose and its frequency (Ahouangninou et al., 2011). Users are unaware of the information on packaging and what it becomes upon use. Some findings have been made in Senegal and Benin where recommendations on the proper use of insecticides and the use of appropriate equipment are not being followed (Cissé et al., 2003; Akogbeto et al., 2005.

These products used are sources of heavy metal contamination (high atomic mass and toxic to biological systems) in food products such as corn and cowpea. They can also cause pollution of the soil, surrounding water points, the death of amphibians, fish, etc.

During this study, producers were interviewed. The information collected made it possible to assess the risks of insecticide use on human health and the environment in Adjohoun. This information also made it possible to characterize the cowpea storage systems used by the various stakeholders, identify the main insecticides used, analyse the methods adopted to use the insecticide and the risks involved, identify the profile of insecticide users and know the different risks they face.

\section{MATERIALS AND METHODS \\ Study area}

The geographical scope of this study is the commune of Adjohoun. This commune (Figure 1), whose total surface is approximately $308 \mathrm{~km}^{2}$ is located in the center of the Ouémé department (territorial division), in the valley and is $32 \mathrm{~km}$ from Porto-Novo, capital city of Benin. It is located between 6 $38^{\circ}$ and $6^{\circ} 48$ 'North latitude and between $2^{\circ}$ $27^{\prime}$ and $2^{\circ} 35$ 'East longitude. It is bounded to the South by the commune of Dangbo, to the North by that of Bonou, to the East by the Commune of Sakété and to the West by the communes of Abomey-Calavi and Zè (Afrique Conseil, 2006).

The commune of Adjohoun has a subequatorial climate characterized by two rainy seasons alternating with two dry seasons. Its relief is marked by the presence of two geomorphological units:

- A low lying plateau whose model has medium strong ripples.

- A floodplain which, in the East-West topo sequence, adjoins the plateau (Afrique conseil, 2006). It extends on both sides of the Ouémé River (Afrique conseil, 2006). More than $80 \%$ of the active population is employed in the agricultural sector (INSAE, 2004).

The vegetation cover of the Adjohoun commune has suffered a severe degradation under the influence of human actions through agricultural activities and bush fires. In spite of the relatively good rainfall in the area, the primary vegetation has disappeared and is replaced with palm groves and Eucalyptus sp. plantation. However, there are shrubby savannahs, grassland and swamps in some areas, which are being filled due to climate change and silting. The only relic of classified forest is in the district of Togbota (about 10 ha). It is home to the red-bellied monkey Cercopithecus erythrogaster: Zin kaka; endangered species, which is protected (Africa Council, 2006).

\section{Methods \\ Methods of operation}

Exploratory field trips allowed to identify and assess the importance of the farms and the different cowpea production sites in the commune. With the support of the CeCPA (Regional Centre for Agricultural Promotion) agents, Producers' Groups have been identified.

Surveys were conducted among 323 cowpea producers ( 0.5 to 3 hectares) selected 
using the shwartz formula. The interviewees were randomly selected in the commune of Adjohoun. For data collection, the questionnaire was validated with the farm managers. The survey itself covered the periods from 20 August to 28 September and from 3 to 25 October 2013. A second visit was made in July and August 2014. The surveys were conducted using semi-structured interviews.

\section{Surveys on small producers}

The questions asked to cowpea producers are related to:

- the knowledge on the pesticides used, i.e. the types of insecticides, compliance with the prescribed doses, the formulations used, the storage time after application of the insecticides and the number of treatments.

- the conditions surrounding the use of the pesticide: The visit of CARDER agents, the effectiveness of the pesticides used, the attitudes of producers before and after using the pesticides, the information they have obtained on pesticide poisoning, the mixtures they make with pesticides, the place where pesticides are stored before use, the destination of empty packaging, the effects they notice upon pesticide use, and finally what they think about pesticide use. The protection and treatment equipment they use and the total number of treatments they perform.

- Data processing

- From the data obtained, descriptive statistics were determined using the Excel 2007 spreadsheet. The charts presented in the document were created using the same software.

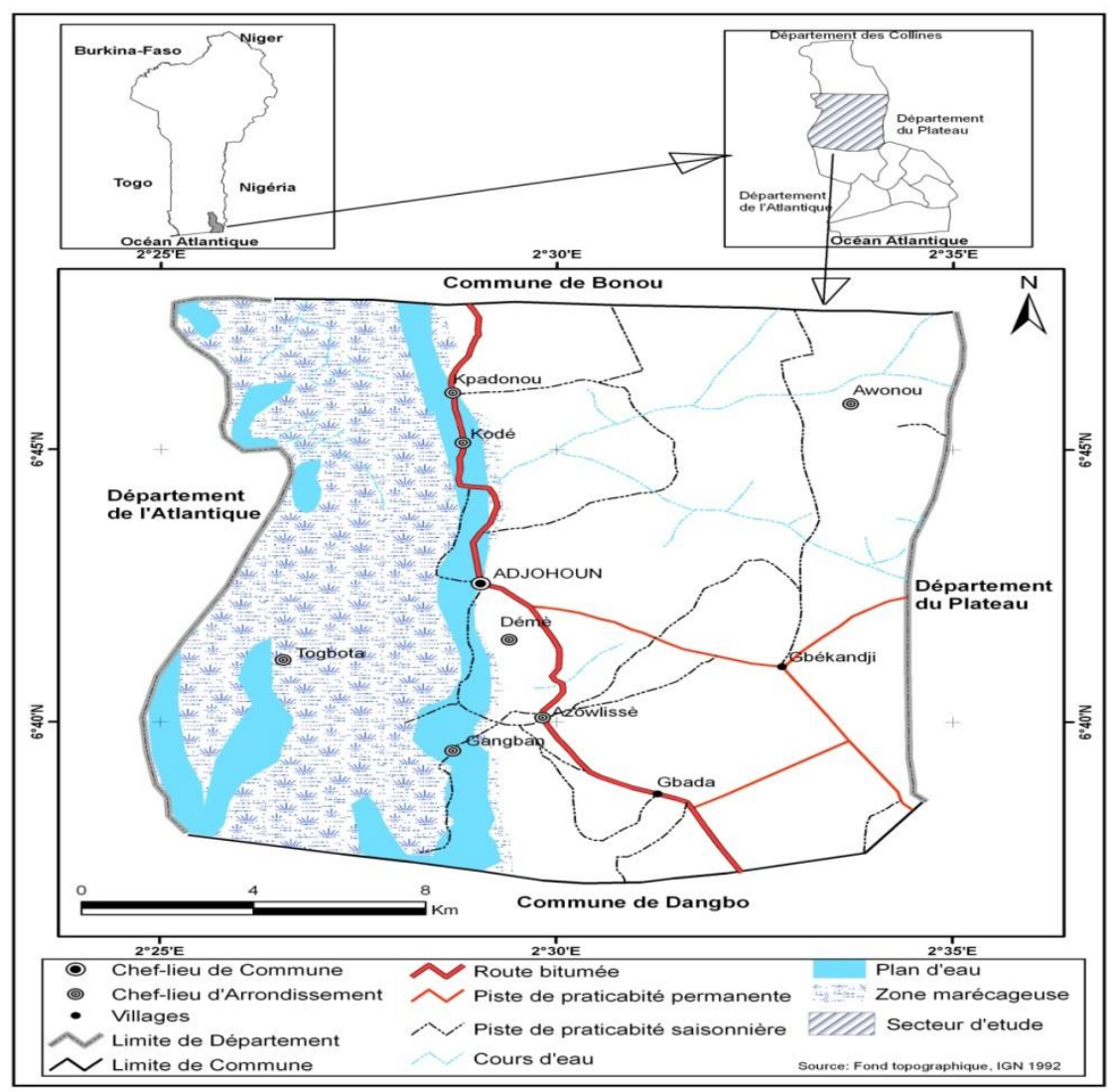

Figure 1: Localization of the Adjohoun commune and its districts. 


\section{RESULTS}

Although Benin has good phytosanitary legislation, there is no means for its implementation. This results in various failures, mainly:

- The pesticides' repackaging in bulk and without labels, especially powdered formulations which are commercialized without any indication. ;

- The uncontrolled handling of phytosanitary products sales points;

- The market stakeholders' lack of qualification, especially retailers and itinerant sellers;

- The lack of control over imports and crossborder transactions (Nigeria and Togo).

\section{Use of phytosanitary products}

Cowpea producers use chemical pesticides and aqueous plant extracts of plants in different ways in their production.

More than half of the surveyed producers use chemical pesticides $(70.3 \%)$, others use aqueous extracts (20\%), and a minority use the mixture of both $(7.7 \%)$. For them, the low rate of the use of the neem aqueous extract is due to the non-availability of this plant in the commune.

The aforementioned mixture of the two products can be done in various ways:

- Chemical pesticide and aqueous extract mixed and sprayed together;

- Aqueous extract followed by the spraying of chemical pesticides;

- Farm splitting into two parts, with a spray of pesticide on one part and aqueous extract on the other to check the effectiveness of the latter.

Various phytosanitary products are used in the treatment of cowpea farms. Sometimes, producers make mixtures of products whose dose, persistence or physicochemical properties are unknown to them. Thus, we note that producers sometimes use different types of products, not to mention the mixtures they prepare in order to have a good crop yield. The farmers get some of these pesticides from CeCPA (Regional Center for Agricultural Promotion) or DAGRI (Directorate General of Agriculture). As far as the DAGRI is concerned, it trains producers on the use of these pesticides. The pesticides that are used in the commune of Adjohoun as well as their family, active ingredients and actions are grouped in Table 1.For the storage of the chemical pesticides, farmers use various locations Figure 2.

Pesticides are stored in higher amounts in attics (62\%) with food products than underground $(25 \%)$ as recommended by the CeRPA (Regional Center for Agricultural Promotion) agents. Some use in-room storage (13\%) which is very dangerous and causes of food poisoning. One of the farmers says: «My eldest child (5 years old) took it, mixed it with beans and ate it with my youngest child ( 2 years old). They all died at the hospital 2 days later ».

Not only does the use of pesticides cause poisoning, but also damage to the environment.

\section{Identification of the main insecticides used and the profile of producers}

Eleven (11) chemicals used by cowpea producers were identified from labels, packaging and statements made during the investigation (Table 1). Among the insecticides used, 10 are labelled in English and 1 in French. The insecticidal formulations were either mixtures based on pyrethrinoid, generally associated with an organophosphate' compound, or endosulfan (of the cyclodiene-organochlorine family), recommended for cotton cultivation. The pesticide formulations identified were divided into nine highly emulsifiable concentrates (EC), six wettable powders (WP) and one granule' (GR). COTALM P 218 EC was the most widely used insecticide by $85 \%$ of producers. As far as the place of supply is concerned, the majority of the producers have their pesticides packaged in the original vials at wholesalers. 
The results of the survey revealed an illiteracy rate of $90 \%$ among producers. Thus only $10 \%$ can read the labels, which are generally in French and English. This leads them not to respect the prescribed doses. According to the results obtained, only $42 \%$ know that there is a possibility of insecticide poisoning when the prescribed dose for the use of the insecticide is not respected.

\section{Environmental problems resulting from the use of pesticides and the aqueous extracts}

The use of these pesticides creates a lot of damage to the environment and to humans as well. More than $3 / 4$ of farmers $(80 \%)$ recognize that chemical pesticides have bad effects on the environment and on their health. Others $(20 \%)$ found that the use of pesticides has no effect. The farmers revealed many detrimental impacts of the use of pesticides on the environment. These impacts include disappearance of the loss of the micro-fauna (worms, termites etc.), which reduces the fertility of the soil. They also cause the death of some rodents, fish etc.

The producers find no bad consequences in the application of the aqueous extract of neem on the environment. They claim that this spraying on cowpea seedlings makes it possible to consume the leaves, the resistance of the plant to drought, the resumption of the plants after harvest.

The producers find no detrimental effects resulting from the use the neem aqueous extract on the environment. They hold the view that this spraying on cowpea seedlings allows the plants' resistance to drought and their recovery after harvest.

\section{Consequences of the use of pesticides on the farmers}

The lack of appropriate protection during the use of pesticides causes health discomforts expressed by producers. During the spraying operations, discomforts have been felt by producers. Table 2 summarizes the various affections.
Headaches and skin problems are the producers' most common complaints when spraying pesticides. In general, all respondents reported experiencing discomforts during and after pesticide applications. The discomforts raised are usually tingling eyes, headaches, digestive problems, skin diseases and respiratory problems, $12.3 \%$ of respondents say they felt no effect. Cases of severe food poisoning (leading to death) have been reported by producers. The investigations allowed us to confirm some of the reported cases.

\section{Producers' protection measures during pesticides spraying}

Spraying insecticides requires some protection. But producers use the protection they think is good. Thus, their protective equipment consists essentially of gloves, boots, masks and mufflers, handkerchiefs, hats and scarves. $23 \%$ of producers do not wear any protective equipment and the recommended combinations are missing. In addition, weather conditions such as rainfall and wind direction are considered by producers prior to application. Figure 3 shows the different protective measures used by producers during spraying operations.

\section{Cleansing place for the sprayer and material}

Three places are commonly used for the cleaning of the sprayer and the material. These are farms, houses and water points (drilling, wells and rivers) Table 3. More than half of the producers wash and cleanse the equipment in the rivers, which is a source of pollution for these different rivers. Some producers $(34.67 \%)$ reuse empty packaging to buy oil, peanut or palm oil and for seed storage. Others (42\%) abandon them on the loose. Some others $(13.33 \%)$ declare burning them with garbage and $10 \%$ bury them in the soil. 
Table 1: Type of chemical pesticides used for the cowpea production in the commune of Adjohoun.

\begin{tabular}{|c|c|c|c|}
\hline Trade names & $\begin{array}{c}\text { User proportion } \\
(\%)\end{array}$ & Active ingredients & Class \\
\hline COTALM P 218 EC & 85 & $\begin{array}{l}\text { Lambdacyhalothrine } \\
\text { Profenofos }\end{array}$ & $\begin{array}{l}\text { pyréthrinoïde } \\
\text { organophosphoré }\end{array}$ \\
\hline DECIS 15 EC & 2 & Deltamethrine & pyréthrinoïde \\
\hline CYPERCAL 50 EC & 2 & Cypermethrine & pyréthrinoïde \\
\hline $\begin{array}{l}\text { COTOFAN } 350 \text { EC } \\
\text { CAPT } 88 \text { EC }\end{array}$ & $\begin{array}{l}2 \\
1\end{array}$ & $\begin{array}{l}\text { Endosulfan } \\
\text { Ac_etamipride } \\
\text { Cypermethrine }\end{array}$ & $\begin{array}{l}\text { Cyclodiène organochloré } \\
\text { organochloré } \\
\text { pyréthrinoïde }\end{array}$ \\
\hline CYPER-D & 1 & Cypermethrine & pyréthrinoïde \\
\hline CYDIM C50 & 1 & Cypermethrine & pyréthrinoïde \\
\hline THIONEX 350 EC & 1 & Endosulfan & Cyclodiène organochloré \\
\hline $\begin{array}{l}\text { CYFLUTHRALM } 318 \\
\text { EC }\end{array}$ & 1 & $\begin{array}{l}\text { Cyfluthrine } \\
\text { Profenofos }\end{array}$ & $\begin{array}{l}\text { Pyréthrinoïde } \\
\text { organophosphoré }\end{array}$ \\
\hline DURSBAN & 1 & Chlorpyriphos-ethyl & organophosphoré \\
\hline Phostoxin & 3 & Phosphore d'aluminium & organophosphoré \\
\hline
\end{tabular}

Source: field survey 2014

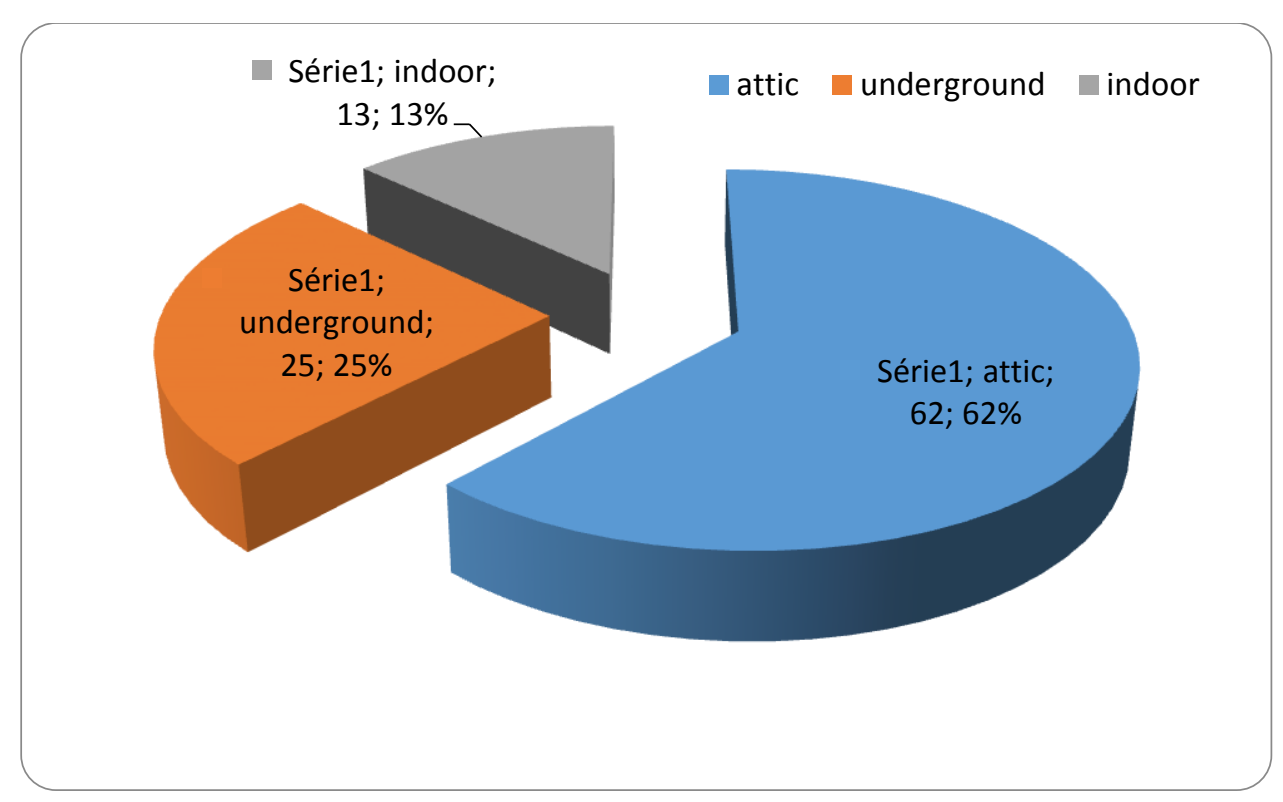

Source: Field survey, 2014

Figure 2: Storage place of chemical pesticides. 
Table 2: Affections related to the spray of chemical pesticides in the commune of Adjohoun.

\begin{tabular}{lcc}
\hline Affections & Number of producers & Rate (\%) \\
\hline Headache & 85 & 26,31 \\
Indigestion & 30 & 9,28 \\
Vomiting & 16 & 4,95 \\
Cold & 55 & 17,02 \\
Desquamation & 80 & 24,76 \\
Ophthalmological (Tingling eyes) & 17 & 5,26 \\
No discomfort & 40 & 12,3 \\
Total & 323 & 100 \\
\hline
\end{tabular}

Source: Field survey, 2014.

Handkerchiefs, scarfs, hat $\square$ smoke helmets and mufflers $\square$ No protection $\square$ Gloves and boots

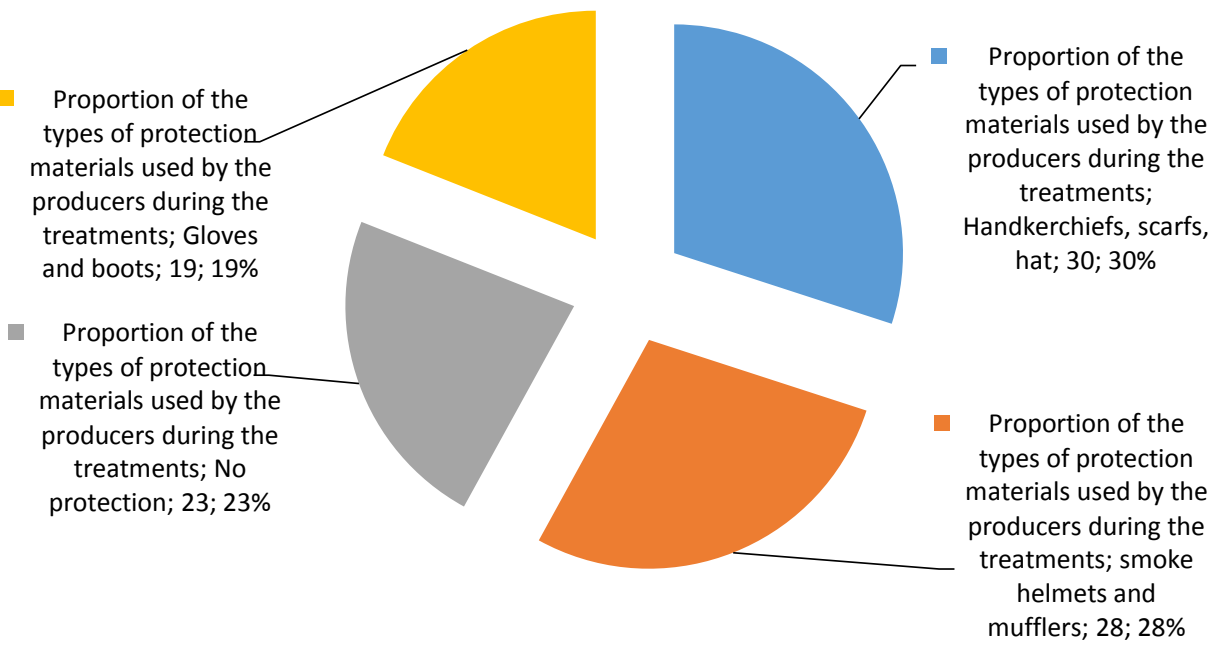

Source: Field survey, 2014.

Figure 3: Producers' protective measures.

Table 3: Frequency of the cleaning places after spraying operations.

\begin{tabular}{cllllll}
\hline \multirow{2}{*}{$\begin{array}{c}\text { Number of producers } \\
(\%)\end{array}$} & \multicolumn{3}{c}{ Sprayer's cleansing place } & \multicolumn{3}{c}{ Material's cleansing place } \\
\cline { 2 - 7 } & Farms & Houses & Rivers & Farms & Houses & Rivers \\
\cline { 2 - 7 } & 10,32 & 14,55 & 75,13 & 8,22 & 11,53 & 80,25 \\
\hline
\end{tabular}

Source: Field survey, 2014.

\section{DISCUSSION}

The insecticides listed in the cowpea survey have already been cited by Obopile et al (2008) and Ahouangninou et al (2011) for their use in vegetable crop protection. It therefore appears that the majority of insecticides used for cowpea are not appropriate (Idrissi et al., 2010). The use of COTALM P 218 EC, a cotton treatment insecticide, to treat cowpea seeds is an example. In addition, the sale of pesticides is mostly carried out in an informal circuit, thus 
escaping the control of the competent authorities. Thus, as observed in several countries in the West African sub-region, the majority of traders are unaware of the existence of institutions responsible for the certification of insecticides (Ahouangninou et al., 2011; Wade, 2003; Kanda et al., 2009; Cissé et al., 2003). The lack of control in the marketing and use of pesticides then results in various manipulations, which has a negative impact on the quality of pesticides.

The lack of control in the marketing of pesticides is also reflected in the users' various handling and reconditioning of formulations. As a result, the recommended dosages of pesticides cannot be respected, increasing the risks to the environment (Cissé et al., 2003; Pazou et al., 2006a; Traore' et al., 2006; Kanda et al., 2009).

Cowpea producers in Adjohoun commune are exposed to diseases due to the different pesticide use methods. These producers use chemical pesticides most of all because they find them very effective. The level of protective equipment use during spreading is low, as already observed in other African countries (Wade, 2003; Williamson et al., 2008). Snelder et al (2008) have noticed the same behaviours among farmers in the Philippines. The failure to wear personal protective equipment could be linked to a lack of financial resources (Matthews, 2007).

Thus, producers are exposed to different pathologies and risks of intoxication (Sanborn et al., 2004; Sousa Passos, 2006), as confirmed by certain symptoms reported by producers in the municipality of Adjohoun. Cases of hospitalization, clinical treatments and symptoms have been reported in 24 countries around the world by producers using chemical pesticides (Tomenson and Matthews, 2009).

The results showed that cowpea producers do not apply any standards. The different dosage levels might present environmental risks and negative consequences are to be feared, which was also reported by Wade (2003) among Niayes producers in Senegal. The results of Assogba-
Komlan et al (2007), which detected residue levels exceeding the accepted standards for organochlorines (DDT, endrin, heptachlor) in vegetables in Ouémé in southern Benin, confirm these findings. Considerations on pesticide use must therefore be seriously addressed to prevent food poisoning related to pesticides.

The listed diseases that affect producers in the municipality are skin irritations, headaches and stomach aches. Discomforts such as vomiting and dizziness are cited by producers as cases that often occur after the chemicals have been applied. PAN Togo (2005), OBEPAB (2006) and Toé (2007) found similar cases of these ailments among cotton producers.

Storage in the room and in the field (underground) are in line with the findings of Cissé et al (2003) in Senegal. Storage in a room could be very dangerous for children, who can handle them, while they are very vulnerable. This method of storage is mainly part of precautionary measures taken to avoid having them stolen and also due to the absence of a storage facility.

The use of empty pesticide boxes after or without washing for other uses poses a health risk for populations. Results at the spray equipment washing sites showed that $80.25 \%$ of producers wash their equipment at water points. Cleaning spray equipment in some water points is a risk factor for this resource and can affect human and animal health (Devez, 2004). This practice is very dangerous for aquatic wildlife and also for consumers of fisheries resources. Pesticide residues have been detected in various fish species in the Ouémé River in Benin (Pazou et al., 2006b). Rainwater, through runoff, carries large quantities of phytosanitary products to the surrounding environment. It should also be noted that pesticide dispersal occurs beyond the agrosystems. Indeed, through the atmospheric movements (wind blowing), the pesticides used can be carried to distant resources in the biotopes. Producers' behaviour must be corrected in order to 
prevent pollution of aquatic ecosystems and to preserve the health of populations.

\section{Conclusion}

The study on the use of plant protection products for cowpea cultivation in Adjohoun municipality shows that the pesticides used are in general initially intended for cotton cultivation. This study made it possible to better understand the various risky practices related to the use of pesticides in the commune of Adjohoun and to draw the detrimental effects on the environment and human health. It revealed that the producers do not comply with the health and environmental standards governing the use of the pesticides. As bad practices, we can mention the non-use of health protection equipment, non-compliance with the guidelines for insecticide concentrations, the use of cotton pesticides on cowpea farms and the cleaning of pesticide spraying equipment at water sources. Thus, for a sustainable exploitation of the natural resources of the commune, we suggest a sensitization of the producers on the use of the pesticides and the further analyses should be carries out (analysis of soil, water, cereals samples etc.) to know the levels of contamination.

\section{REFERENCES}

Ahouangninou C, Fayomi BE, Martin T. 2011. Assessment of the health and environmental risks of phytosanitary practices of market gardeners in the rural commune of Tori-Bossito (South Benin). Cahiers Agricultures, 20(3): 216-222.

Akogbeto MC, Djouaka R, Noukpo H. 2005. Use of agricultural insecticides in Benin. Bulletin of the Exotic Pathology Society, 98: 400-405.

Assogba-Komlan F, Anihouvi P, Achigan E, Sikirou R, Boko A, Adje C. 2007. Cultivation practices and anti-nutritional elements (nitrates and pesticides) content of Solanum macrocarpum in southern Benin. African Journal of Food, Agriculture, Nutrition and Development, 7: 1-21.
Cissé I, Tandia A, Fall ST, Diop EHS. 2003. Uncontrolled use of pesticides in periurban agriculture: the case of the Niayes area in Senegal. Cahiers Agricultures, 12(3): 181-186.

Devez A. 2004. Characterization of the risks induced by agricultural activities on aquatic ecosystems. Doctoral thesis: École Nationale du Génie Rural des Eaux et des Forêts (ENGREF), Hydrosciences Montpellier (HSM), P. 112.

Idrissi M, Aït DN, Ouammi L, Rhalem N, Soulaymani A, Soulaymani RB. 2010. Acute pesticide poisoning: Data from the Anti-Poison Centre of Morocco (19892007). Toxicology Morocco, 4(1): 5-7

AFRICA COUNCIL. 2006. Monograph of the municipality of Adjohoun, Africa Council, P.44.

Kanda M, Wala K, Batawila K, DjaneyeBoundjou G, Ahanchede A, Akpagana K. 2009. Peri-urban market gardening in Lomé: cultural practices, health risks and spatial dynamics. Cah Agric, 18: 356363. doi: 10.1684/agr.2009.0319.

Matthews GA. 2008. Attitudes and behaviours regarding use of crop protection products-A survey of more than 8500 smallholders in 26 countries. Crop. Prot., 27: 834-846.

OBEPAB (Organisation Béninoise pour la Promotion de l'Agriculture Biologique). 2006. Identification of health and environmental problems related to persistent organic pollutants (POPs). Study report, OBEPAB, Cotonou, Benin, $\mathrm{p} 42$.

Obopile M, Munthali DC, Matilo B. 2008. Farmers' knowledge, perceptions and management of vegetable pests and diseases in Botswana. Crop. Prot., 27: 1220-1224.

PAN (Pesticide Action Network) Togo. 2005. Socio-economic, health and environmental impact study of the use of the Pops in Davier north of Lomé (maritime region), Togo. Study report. 
IPEP. Lom: Pesticide action network Togo, p.281.

Pazou EYA, Boko M, Van Gestel CAM, Ahissou $\mathrm{H}$, Lalèyè $\mathrm{P}$, Akpona $\mathrm{S}$, Van Hattum B, Swart K, Van Straalen NM. 2006a. Organochlorine and organophosphorate pesticide residues in the Ouémé river catchment in the Republic of Benin. Environment Environment International, 32(5): 616623.

Pazou EYA, Lalèyè P, Boko M, Van Gestel CAM, Ahissou H, Akpona S, Van Hattum B, Swart K, Van Straalen NM. 2006b. Contamination of fish by organochlorine pesticide residues in the Ouémé river catchment in the Republic of Benin. Environment International, 32(5): 594-599.

Sanborn M, Cole D, Kerr K, Akil C, Sanin LH, Bassil K, 2004. Pesticides literature Review. Ontario College of Family Physicians: Toronto.

Snelder DJ, Masipiquena MD, from Snoo GR, 2008. Risk assessment of pesticide use by smallholder farmers in the Cagayan valley (Philippines). Crop. Prot., 27: 747-762.

Sousa Passos CJ. 2006. Human exposure to pesticides: a risk factor for suicide in Brazil? Vertigo La Revue Électronique en Sciences de l'Environnement, 7 : 1-18.
Traoré SK, Mamadou K, Dembele A, Lafrance P, Mazelliert P, Houenou P, 2006. Contamination of groundwater by pesticides in agricultural regions in Côte d'Ivoire (central, southern and southwestern). African Journal of Environmental Sciences, 1: 1-9.

Tomenson JA, Matthews GA, 2009. Causes and types of health effects during the use of crop protection chemicals: data from a survey of over 6,300 smallholder applicators in 24 different countries. Int Arch Occ Env Hea. 82: 935-949.

Toé MA. 2007. Use of chemical pesticides in market gardening and cotton cultivation in the eastern region of Burkina Faso, 2005-2006 and 2006-2007 crop year. Study report. Bobo Dioulasso, Burkina Faso: Institut de Recherche en Sciences de la Santé (IRSS), P. 60.

Wade CS, 2003. The use of pesticides in periurban agriculture and its impact on the environment. Thesis of Pharmacy, Dakar.

http://indexmedicus.afro.who.int/iah/fullt ext/wade_cheikh.pdf

Williamson S, Ball A, Pretty J, 2008. Trends in pesticide use and drivers for safer pest management in four African countries. Crop. Prot., 27: 1327-1334. 